\title{
Using mobile phones to promote maternal and child health: knowledge and attitudes of primary health care providers in southwest Nigeria
}

\author{
Mobolanle R Balogun ${ }^{1}$ @ , Godfred O Boateng ${ }^{2}$, Yenupini J Adams ${ }^{3}$, Bukola Ransome-Kuti ${ }^{4}$, Adekemi Sekoni ${ }^{1}$, Ellis A \\ Adams $^{3}$ \\ 1 Department of Community Health \& Primary Care, College of Medicine, University of Lagos, Lagos, Nigeria, ${ }^{2}$ Department of Kinesiology, College of \\ Nursing and Health Innovations, The University of Texas at Arlington, Arlington, Texas, USA, ${ }^{3}$ Keough School of Global Affairs, University of Notre \\ Dame, Notre Dame, Indiana, USA, ${ }^{4}$ Department of Paediatrics, Lagos State University Teaching Hospital, Lagos, Nigeria \\ Keywords: mhealth, primary health care, nigeria, maternal and child health \\ https://doi.org/10.29392/001c.13507
}

\section{Journal of Global Health Reports}

Vol. 4, 2020

\begin{abstract}
Background
The use of mHealth by primary health care providers is a unique opportunity to improve maternal and child health in Sub-Saharan Africa. However, few studies have examined the effects of primary health care providers' knowledge and attitudes of mHealth for maternal and child health promotion in low-resource settings. Therefore, this study assesses the knowledge and attitudes of primary health care providers on the use of mobile technologies such as internet-enabled smartphones for maternal and child health services.
\end{abstract}

\section{Methods \\ We used data from a cross-sectional study of seven urban local government areas in Lagos, Nigeria. A total of 518 primary health care providers were surveyed for information on the use of mobile technologies, attitudes, and actual use of mobile technologies for maternal and child health services. Data were analyzed using descriptive and multivariable linear and logistic regression models.}

\section{Results}

Our study showed that smartphone ownership is not a predictor of high mHealth knowledge; however, having an internet-enabled smart phone was a strong predictor of higher knowledge of mHealth (regression coefficient, $§=1.20$, 95\% confidence interval, $\mathrm{CI}=0.61-1.79)$ among primary health care providers. Owning a smartphone $(\Omega=1.00,95 \%$ $C I=0.12-1.89)$ and having internet-enabled phone $(~(==1.14,95 \% C I=0.18-2.10)$ were both predictors of positive mHealth attitude. Primary health care providers with higher scores on mHealth knowledge were 1.32 times more likely to use mHealth for maternal and child health services. Similarly, those with positive attitude towards mHealth were 1.15 times more likely to use mobile technology for maternal and child health services.

\section{Conclusion}

The results suggest the use of mHealth tools by primary health care providers to render maternal and child health services is affected by their knowledge and attitude towards mHealth. Interventions that focus on increasing mobile technologies with internet enabled devices like smartphones are needed to improve knowledge, attitudes, and use of mHealth in maternal and child health services.

Mobile Health (mHealth) technologies are widely being promoted as tools to decrease maternal and child mortality around the world. mHealth is the application of mobile technologies and wireless communication techniques to improve health and health outcomes. ${ }^{1}$ These mobile technologies include mobile phones, personal digital assistants, smartphones, portable media players, handheld and ultraportable computers such as tablet PCs. ${ }^{2}$ The applications on these devices enable communication through text mes- sages, photos and videos, telephone and internet access, and multi-media playback. ${ }^{2}$ The ubiquitous nature of mobile communication and the ease of its usage has prompted the use of mobile applications in the management of diseases and promotion of healthy behaviors.

Various mHealth technologies are being used as tools in the promotion of maternal and child health. These tools are used in communities to provide antenatal, delivery, and postnatal care. ${ }^{3}$ A plethora of research shows that mHealth 
interventions can be useful for improving coverage of community-based maternal, neonatal, and child health services when there are shortages of health care professionals. ${ }^{4}$ In a systematic review of literature on the use of mHealth for maternal health interventions, several studies focusing on low and middle-income countries supported the use of mHealth for data collection, appointment reminders, health promotion, and provider-to-provider communications. ${ }^{5}$ In another review on use of mHealth for under five child health in low- and middle-income countries, text message interventions were used to address patient medication compliance, demand for healthcare services, compliance with healthcare appointments and maternal education and behaviors. ${ }^{6}$

Existing evidence shows that mHealth applications may be useful for improving maternal, neonatal and child health, including increased antenatal care attendance, facility use and skilled attendance at birth, postnatal care attendance, and immunization rates. ${ }^{7-9}$ An SMS-based system implemented among community health workers in Rwanda resulted in a $27 \%$ increase in health care facility deliveries within a 12 -month period. ${ }^{10}$ In Zanzibar, mobile phone interventions significantly increased skilled delivery attendance in primary healthcare facilities. ${ }^{11}$ mHealth interventions have also increased coverage of services such as vitamin supply to pregnant women and postnatal home visits in India. ${ }^{7}$ Results of one systematic review even showed that SMS support during pregnancy, compared with routine prenatal care, decreased the risk of perinatal death in children of mothers who received the intervention. ${ }^{12}$ A metaanalysis by Lee et al. also showed improved breastfeeding rates with SMS/cell phone interventions. ${ }^{12}$

The application of mobile phones by primary health care (PHC) providers is a unique platform to improve maternal and child health in Sub-Saharan African countries. This is because PHC providers are the closest providers of health care to expectant and postpartum mothers. Improved communication strategies between PHC providers and pregnant or postpartum women discourage harmful practices that could increase maternal and neonatal morbidity and mortality. ${ }^{13}$ Given the acceptability, widespread use, and effectiveness of mHealth interventions, they have the potential to decrease maternal and child mortality in severely burdened countries in Sub-Saharan Africa such as Nigeria.

Nigeria currently accounts for nearly $20 \%$ of all global maternal deaths. ${ }^{14}$ The country's 2015 maternal mortality ratio (MMR) of 814 maternal deaths per 100,000 live births is higher than the regional figure of 546 deaths $/ 100,000$ live births for sub-Saharan Africa and much higher than the global estimate of 216 deaths /100,000 live births. ${ }^{15}$ Neonatal and under-five mortality rates are also very high in Nigeria. The 2017 neonatal mortality rate (NMR) for Nigeria was 32.90 deaths/1000 live births, compared to the global estimate of 18 deaths/1000 live births. ${ }^{16,17}$ Likewise, Nigeria's under-five child mortality rate of 100.2 deaths/1000 live births, is more than 2.5 times higher than the global estimate of 39.1 deaths/1000 live births. ${ }^{16,17}$

However, although mHealth initiatives are being developed and implemented around the world to improve maternal and child health, ${ }^{1}$ their adoption and implementation in Sub-Saharan African countries have been minimal. ${ }^{18}$ There is a lack of emphasis of studies on the adoption of mHealth in the delivery of maternal and child health services among health care providers in low-resource settings. ${ }^{19}$ The few studies focusing on providers underscore challenges such as technological problems, internet access, electricity, and phone maintenance. ${ }^{3}$ Other studies have shown that ease of use, cost, time, privacy/security concerns, familiarity of technology, and risk-benefit assessments are factors influencing adoption among healthcare professionals. ${ }^{2}$

In addition to the barriers mentioned, PHC providers' knowledge and attitudes toward mHealth influence adoption and utilization in delivering maternal and child health services. However, few studies have examined the effects of knowledge and attitudes on the use of mHealth technologies among PHC providers in low-resource settings. The few studies on health care provider knowledge and attitudes have focused on knowledge and attitudes towards the use of computers and information technology. ${ }^{20-23}$ It remains unknown whether knowledge and attitudes are associated with adoption or use of mHealth among primary health care providers. Therefore, the objectives of this study were to 1) assess whether primary health care providers access to mobile phones or internet-enabled smartphones resulted in higher knowledge of mHealth and positive attitudes towards mHealth and 2) assess the effect of higher knowledge and positive attitude towards mHealth on the use of mobile technology to promote maternal and child health.

\section{METHODS}

\section{DATA DESCRIPTION}

Data for this study were drawn from a cross-sectional study implemented in seven urban local government areas (LGAs) in Lagos State, southwest Nigeria between September and October 2014. A total of 518 PHC workers (comprising doctors, nurses, midwives, community health officers and community health extension workers) were selected consecutively at primary health care centers. A structured, selfadministered questionnaire was used to collect data (Appendix S1 in the Online Supplementary Document). The questionnaire was developed from review of similar studies, ${ }^{24-26}$ and pretested among PHC workers in a LGA outside of the study sites. Data collected included socio-demographic characteristics, mobile phones utilization, knowledge of the use of mobile phones in promoting maternal and child health, and attitudes towards the use of mobile phone to promote maternal and child health.

Outcome variables: Three outcome variables were examined in this study. This included knowledge of mobile phone use to promote maternal and child health; attitude towards the use of mobile phones to promote maternal and child health, and actual usage of phones to promote maternal and child health.

Knowledge of mobile phone use to promote maternal and child health (mHealth Knowledge Scale): This measure was assessed as a scale based on eight questions derived from literature review. ${ }^{24-26}$ Participants were then asked to respond to questions that reflected the multiple uses of mobile phones for maternal and child health service delivery. This included the use of mobile phones to (1) moni- 
tor pregnancies, (2) notify due and missed visits, (3) ensure drug adherence, (4) send reminders on immunization dates, (5) send health tips, (6) receive alerts for urgent and lifethreatening events, (7) coordinate emergency transportation, and (8) provide education on maternal and child nutrition. The questions were assessed to reflect a common knowledge domain. ${ }^{1}$ Response to these questions were coded as (0) No and (1) Yes. These items were then assessed psychometrically into the mHealth Knowledge scale.

Attitude towards the use of mobile phones to promote maternal and child health (mHealth Attitude Scale): This measure was assessed as a scale based on 11 questions derived from literature review. ${ }^{24-26}$ The questions were assessed to reflect a domain on attitude towards the use of mobile phones for the promotion of maternal and child health. Participants were asked to respond to questions that reflected their attitude towards its use. This included (1) the use of phone as a good way to promote maternal and child health, (2) the need to provide special training to use phones for care services, (3) the effectiveness of using the phone to monitor mother and child before and after delivery, (4) the accessibility of text messages through mobile phones, (5) cost effectiveness of using phones to communicate care for mother and child, (6) use of phone for appointment, (7) use of phones to promote confidentiality between healthcare providers and patient (8) use of phone to promote trust between health workers and mothers, (9) willingness to use phone to provide services for mothers and children, (10) willingness to encourage other care providers to use their phones to render services to mothers and their children, and (11) use of mobile phones to promote efficiency of service delivery. Response to these questions were based on a Likert type scale with ratings such as: 1-strongly disagree, 2- disagree, 3-neither agree nor disagree, 4-agree, 5 - strongly disagree. These items were assessed psychometrically to create the mHealth Attitude Scale.

Actual use of mobile phone for maternal and childcare services: In order to know whether healthcare providers had used phones at the health care center for care services, participants were asked "have you ever used your mobile phone to render any health service to pregnant women or children? Responses to this question were coded into a binary (0) No and (1) Yes.

Explanatory Variables: The main independent variables examined in this paper were ownership of a smart phone and having an internet-enabled phone. Both questions had binary responses which were coded as (0) No and (1) Yes. We adjusted for a number of confounding variables. This included the cadre of the primary health care practitioner, their level of education, the nature of the healthcare center, sex, age, tribe, and marital status. The Cadre of participant was coded as (1) Community health extension worker (CHEW), (2) Community health officer (CHO), (3) Doctor, (4) Nurse/Mid-Wife, and (5) Other health attendants. Education was coded as (1) Low (Primary/Secondary Education) (2) High (Tertiary Education). Health center was dichotomized into (1) Private health center and (2) Public health center. Sex was grouped into (1) Female and (2) Male. Age was used as a continuous variable. Tribe of participants was coded as (1) Yoruba (2) Others, (3) Igbo, and (4) Hausa. Marital status was coded into (1) Married and (2) Not mar- ried.

\section{DATA ANALYSIS}

First, to determine the latent factor structure of the outcome variables, knowledge and attitudes towards use of mobile technologies for maternal health care services, we examined inter-item and item-total correlations. We then assessed items for internal consistency using Cronbach's alpha. Confirmatory factor analysis was used to assess the hypothesized factor structure of the knowledge variable assuming satisfactory fit indices if RMSEA $<0.06, \mathrm{CFI}>0.95$, TLI $>0.95$, and SRMR $<0.08 .^{27}$ The threshold for acceptable factor loadings was $>0.30 .{ }^{28}$ Items for Attitude towards the use of mobile technologies for maternal health care services were examined for both inter-item and item-total correlations, which resulted in the removal of two items.

An exploratory factor analysis showed that two of the items $(9,10)$ did not fit the model, hence, they were removed and re-estimated. This culminated in a unidimensional factor structure, suggesting the battery of questions on attitude could be measured as a single latent variable. The variable was assessed to assume satisfactory model fitness if RMSEA $<0.06, \mathrm{CFI}>0.95$, TLI $>0.95$, and SRMR $<0.08 .^{27}$ Both scale scores were created by the sum of items in each scale.

Descriptive and multivariate analyses were used to assess the relationship between the outcome variables and explanatory variables. Descriptively, we estimated proportions for categorical variables and means and standard deviations for continuous variables. In order to assess the distribution of independent variables over the outcome variables that were continuous, we used the student's t-test and analysis of variance for categorical variables. The binomial distribution of the third outcome variable - actual use on phone for maternal and childcare services - allowed us to conduct Pearson Chi-Squared associations between the outcome variable and the explanatory variables. Since, the omnibus Pearson chi-square value does not indicate which categories contribute to statistical significance for categorical variable with more than two categories, we used logistic regression models. This was followed by multiple linear regression analysis using ordinary least squares for the two continuous outcome variables and the logit link function for binary outcome variable. Analyses were performed using STATA v.14.0. ${ }^{29}$ The results were assessed to be significant at $P<0.05$.

\section{ETHICS}

Ethical approval to carry out this study was obtained from the Health Research and Ethic Committee of Lagos University Teaching Hospital (LUTH) with approval number: ADM/ DCST/HREC/APP/1881. Each participant provided a verbal informed consent. Confidentiality was ensured by not using identifiers. Study data were stored in password-protected laptops controlled by MRB and GOB. 
Table 1. Descriptive results of the distribution of knowledge, attitude and use of mHealth among primary health care providers in Nigeria

\begin{tabular}{|c|c|c|c|c|c|c|c|c|}
\hline \multirow[t]{2}{*}{ Variables } & & \multicolumn{2}{|c|}{$\begin{array}{l}\text { Knowledge of } \\
\text { mHealth }\end{array}$} & \multicolumn{2}{|c|}{$\begin{array}{l}\text { Attitude to } \\
\text { mHealth }\end{array}$} & \multicolumn{2}{|c|}{ Use of mHealth } & \multirow[t]{2}{*}{$\begin{array}{l}\text { Chi-square } \\
\left(x^{2}\right)\end{array}$} \\
\hline & & $\%$ & T-value & Mean & $\begin{array}{l}\mathrm{T} \text { - } \\
\text { value }\end{array}$ & $\begin{array}{l}\text { No } \\
\text { (\%) }\end{array}$ & $\begin{array}{l}\text { Yes } \\
(\%)\end{array}$ & \\
\hline \multirow[t]{2}{*}{ Own smartphone } & No & 13.53 & $4.07^{* * *}$ & 27.0 & $3.30^{* *}$ & 36.79 & 63.79 & $7.98^{* *}$ \\
\hline & Yes & 14.48 & & 28.3 & & 23.13 & 76.87 & \\
\hline \multirow[t]{2}{*}{$\begin{array}{l}\text { Have internet on } \\
\text { phone }\end{array}$} & No & 13.09 & $5.64^{* * *}$ & 26.82 & $3.39^{* *}$ & 37.23 & 62.77 & $7.44^{* * *}$ \\
\hline & Yes & 14.52 & & 28.33 & & 23.58 & 76.42 & \\
\hline \multirow[t]{2}{*}{ Education } & Low & 13.18 & $4.90^{* * *}$ & 27.98 & 0.18 & 41.18 & 58.82 & $12.05^{* * *}$ \\
\hline & High & 14.4 & & 28.07 & & 23.09 & 76.91 & \\
\hline \multirow[t]{2}{*}{ Health center } & Private & 14.13 & 1.16 & 27.74 & 1.57 & 30.49 & 69.51 & $3.99^{*}$ \\
\hline & Public & 14.36 & & 28.29 & & 22.71 & 77.29 & \\
\hline \multirow[t]{2}{*}{ Sex } & Female & 14.11 & $3.19^{* *}$ & 27.95 & 1.21 & 25.42 & 74.58 & 0.487 \\
\hline & Male & 14.93 & & 28.49 & & 28.87 & 71.13 & \\
\hline \multirow[t]{2}{*}{ Marital status } & Married & 14.23 & 0.52 & 28.39 & $2.83^{* *}$ & 22.88 & 77.12 & $5.87^{*}$ \\
\hline & $\begin{array}{l}\text { Not } \\
\text { married }\end{array}$ & 14.34 & & 27.34 & & 32.93 & 73.94 & \\
\hline
\end{tabular}

* $P$-value $<0.05 ; *$ ** $P$-value $<0.01 ;$ ***** $P$-value $<0.001$

\section{RESULTS}

\section{MHEALTH KNOWLEDGE AND ATTITUDE SCALES}

Item-test correlation for the mHealth knowledge items ranged from 0.59 to 0.74 ; item-total correlation ranged from 0.43 to 0.61 . The Cronbach's alpha, which tested the internal consistency of the eight items was 0.85 , above the often recommend threshold of 0.70 . We hypothesized that the eight items will form a unidimensional scale and used confirmatory factor analysis for assessment. The eight items did form a unidimensional scale based on a confirmatory factor analysis with factor loadings ranging from 0.63 to 0.91 and satisfactory fit indices [chi-square, $\chi^{2}(20)$ $=69.84, P<.03$; root mean square error of approximation, RMSEA=0.07 (confidence interval, $\mathrm{CI}=0.05-0.09$ ); comparative fit index, CFI=0.98; Tucker-Lewis index, TLI=0.98; standardized root mean square residual $=0.05]$. The scale scores ranged from 8-16. Higher scores suggest better knowledge about the use of mobile phones for maternal and childcare, while lower scores suggested poor knowledge.

Of the 11 mHealth Attitude items, two of the items were not consistent with the conceptualization of the attitude domain; hence, they were removed. Due to the limited information about attitude, we estimated an exploratory factor analysis to determine the factor structure. This produced a unidimensional scale, but required the removal of items two additional items (9 and 10), leaving 7 items with satisfactory fit indices $\left[\chi^{2}(14)=29.96, \mathrm{p}<.03\right.$; RMSEA=0.05 (CI: 0.02, 0.07); CFI=0.98; TLI=0.97; standardized root mean square residual $=0.03]$. Item-test correlation for the items ranged from 0.46 to 0.74 ; item-total correlation ranged from 0.24 to 0.60 . The Cronbach's alpha was 0.72 , with factor loadings ranging from 0.30 to 0.70 . The scale scores ranged from 13 to 35 .

\section{DESCRIPTIVE AND BIVARIATE RESULTS}

In this study, knowledge of mHealth among primary health care providers had a score range of $8-16$, with a mean of 14.26 and a standard deviation of 2.28. Higher scores suggest increased knowledge. The measure on Attitude towards use of mobile phone for mHealth services had a score range of $13-35$, with a mean of 28.06 and a standard deviation of 3.95. About 7 out of every 10 healthcare providers (73.94\%) reported they had ever used mobile phones to render any service to pregnant women or children. Eight of every ten (77.61\%) of the health care providers owned a smart phone; the same proportion had internet on their phone (81.85\%). Of the health care professionals, $9.85 \%$ were community health officers, $17.18 \%$ were doctors, $51.54 \%$ were nurses or mid-wives, and $6.99 \%$ fell into the allied health professionals. Eight of every 10 primary health care providers had high education (tertiary), about $57 \%$ worked in the public sector, $81.27 \%$ were females, $68.34 \%$ were married, and majority (82.24\%) were from the Yoruba tribe. The age of primary health care providers ranges from 14-69 years, with a mean of 36.01 and a standard deviation of 3.95 .

Table 1 shows the distribution of outcome variables over covariates. The mean scores of mHealth knowledge was significantly greater for those who owned smartphone vs. those who did not own one ( 14.48 vs. $13.53 ; P<0.001)$, had internet-enabled phones vs. those who did not have $(14.52$ vs. $\left.13.09 * ; \mathrm{P}^{*}<0.001\right)$, high education vs. low education 
Table 2. A linear regression model showing the predictors of mHealth knowledge among primary health care providers

\begin{tabular}{|c|c|c|c|c|}
\hline \multirow[t]{2}{*}{ Variables } & & Model 1 & Model 2 & Model 3 \\
\hline & & B (95\%Cl); $P$-value & B (95\%Cl); $P$-value & B (95\%Cl); $P$-value \\
\hline Own smartphone & Yes & $0.49(-0.06,1.05) ; 0.08$ & $0.36(-0.16,0.89) ; 0.18$ & $0.38(-0.14,0.91) ; 0.150$ \\
\hline $\begin{array}{l}\text { Have internet on } \\
\text { phone }\end{array}$ & Yes & $1.21(0.58,1.82) ; 0.001$ & $1.21(0.62,1.81) ; 0.001$ & 1.20 (0.61, 1.79); 0.001 \\
\hline \multirow[t]{5}{*}{ Cadre } & CHEW & & Ref. & Ref. \\
\hline & $\mathrm{CHO}$ & & $0.81(0.03,1.59) ; 0.04$ & $0.66(-0.11,1.43) ; 0.09$ \\
\hline & Doctor & & $1.37(0.72,2.02) ; 0.001$ & $1.24(0.54,1.96) ; 0.001$ \\
\hline & $\begin{array}{l}\text { Nurse/ } \\
\text { midwife }\end{array}$ & & $0.54(-0.11,1.19) ; 0.11$ & $0.51(-0.15,1.16) ; 0.13$ \\
\hline & Others & & $\begin{array}{l}-0.74(-1.76,0.29) \\
0.16\end{array}$ & $-0.68(-1.73,0.36) ; 0.19$ \\
\hline \multirow[t]{2}{*}{ Education } & Low & & Ref. & Ref. \\
\hline & High & & $\begin{array}{l}1.08(0.44,1.72) ; \\
0.001\end{array}$ & $0.99(0.32,1.65) ; 0.03$ \\
\hline \multirow[t]{2}{*}{ Health Center } & Private & & Ref. & Ref. \\
\hline & Public & & $0.09(-0.29,0.49) ; 0.63$ & $0.04(-0.36,0.45) ; 0.83$ \\
\hline \multirow[t]{2}{*}{ Sex } & Female & & & Ref. \\
\hline & Male & & & $0.19(-0.37,0.74) ; 0.51$ \\
\hline Age & Age & & & $0.02(0.01,0.05) ; 0.02$ \\
\hline \multirow[t]{4}{*}{ Tribe } & Yoruba & & & Ref. \\
\hline & Igbo & & & $-0.43(-0.96,0.08) ; 0.10$ \\
\hline & Hausa & & & $-1.82(-4.39,0.74) ; 0.16$ \\
\hline & Others & & & $-0.29(-1.32,0.72) ; 0.57$ \\
\hline \multirow[t]{2}{*}{ Marital status } & Married & & & Ref. \\
\hline & Not married & & & $0.35(-0.07,0.78) ; 0.10$ \\
\hline \multirow[t]{5}{*}{ Intercept } & Intercept & $\begin{array}{l}12.89(12.3,13.5) \\
0.001\end{array}$ & $10.41(9.1,11.8) ; 0.001$ & $\begin{array}{l}9.49 \text { (7.94, 11.07); } \\
0.001\end{array}$ \\
\hline & $\mathrm{N}$-size & 518 & 518 & 518 \\
\hline & R-square & 0.065 & 0.156 & 0.177 \\
\hline & Adj. R-square & 0.06 & 0.142 & 0.154 \\
\hline & RMSE & 2.215 & 2.117 & 2.103 \\
\hline
\end{tabular}

Ref.: reference categories; ß: Beta coefficient; CI: confidence interval, RMSE: root mean square error, CHEW: community health extension worker, CHO: community health officer.

(14.4 vs. $13.18 ; P<0.001)$, and females vs. males (19.93 vs. 14.11). For attitude towards mHealth, the mean scores were higher for those owned smartphones vs. those who did not own ( 28.3 vs. $27 ; P<0.001)$, had internet-enabled phones vs. those without (28.33 vs.26.82; $P<0.001)$, and the married vs. not married (28.39 vs. $27.34 ; P<0.01)$. This suggesting a positive attitude for those with higher scores. The proportion of primary health care providers who had ever used mobile phones to render maternal and child health services was higher for those who owned smartphone (76.87\%) than those who did not (63.79\%). Similarly, about $76.42 \%$ of primary health care providers with internet-enabled phones to render maternal and child health services compared to $62.77 \%$ of those with no internet. About $76.91 \%$ of highly educated primary health care providers had ever provided
mHealth services compared to $58.82 \%$ of those with low education. About $77.29 \%$ of primary health care providers in the public health sector had ever provided mHealth services relative to $69.51 \%$ of those in the private health sector. About $77.12 \%$ of primary health care providers who were married had ever provided mHealth services compared to $73.94 \%$ of those not married.

\section{PREDICTING MHEALTH KNOWLEDGE, ATTITUDE AND USAGE}

Table 2 shows the multivariate linear regression results examining the association between ownership of smartphone and internet-enabled phone with mHealth knowledge after controlling for demographic factors. In model 
Table 3. A linear regression model showing the predictors of attitude towards mHealth among primary health care providers

\begin{tabular}{|c|c|c|c|c|}
\hline \multirow[t]{2}{*}{ Variable } & & Model 1 & Model 2 & Model 3 \\
\hline & & B (95\%Cl); $P$-value & B (95\%Cl); $P$-value & B (95\%Cl); $P$-value \\
\hline Own smartphone & Yes & $0.95(0.04,1.85) ; 0.04$ & $0.96(0.06,1.86) ; 0.04$ & $0.97(0.09,1.85) ; 0.03$ \\
\hline $\begin{array}{l}\text { Have internet on } \\
\text { phone }\end{array}$ & Yes & $1.09(0.12,2.07) ; 0.03$ & $1.14(0.16,2.11) ; 0.02$ & $1.00(0.02,1.98) ; 0.05$ \\
\hline \multirow[t]{5}{*}{ Cadre } & CHEW & & Ref. & Ref. \\
\hline & $\mathrm{CHO}$ & & $0.61(-0.89,2.11) ; 0.43$ & $-0.22(-1.74,1.29) ; 0.77$ \\
\hline & Doctor & & $0.49(-0.83,1.82) ; 0.46$ & $-0.29(-1.69,1.11) ; 0.68$ \\
\hline & $\begin{array}{l}\text { Nurse/ } \\
\text { Midwife }\end{array}$ & & $0.84(-0.28,1.96) ; 0.14$ & $0.42(-0.71,1.56) ; 0.46$ \\
\hline & Others & & $-0.09(-1.60,1.42) ; 0.91$ & $-0.15(-1.65,1.34) ; 0.84$ \\
\hline \multirow[t]{2}{*}{ Education } & Low & & Ref. & Ref. \\
\hline & High & & $-0.23(-1.29,0.83) ; 0.67$ & $-1.09(-2.20,0.01) ; 0.05$ \\
\hline \multirow[t]{2}{*}{ Health center } & Private & & Ref. & Ref. \\
\hline & Public & & $0.77(-0.03,1.56) ; 0.06$ & $0.42(-0.38,1.22) ; 0.31$ \\
\hline mHealth Knowledge & & & & $0.27(0.10,0.45) ; 0.003$ \\
\hline \multirow[t]{2}{*}{ Sex } & Female & & & Ref. \\
\hline & Male & & & $0.79(-0.27,2.47) ; 0.16$ \\
\hline Age & Age & & & $0.06(0.02,0.10) ; 0.004$ \\
\hline \multirow[t]{4}{*}{ Tribe } & Yoruba & & & Ref. \\
\hline & Igbo & & & $-0.56(-1.94,0.61) ; 0.38$ \\
\hline & Hausa & & & $-0.51(-3.72,2.42) ; 0.74$ \\
\hline & Others & & & $-0.31(-1.94,1.20) ; 0.69$ \\
\hline \multirow[t]{2}{*}{ Marital Status } & Married & & & Ref. \\
\hline & Not married & & & $-0.67(-1.46,0.12) ; 09$ \\
\hline \multirow[t]{5}{*}{ Intercept } & Intercept & $\begin{array}{l}\text { 26.42(25.55, 27.29); } \\
0.001\end{array}$ & $\begin{array}{l}25.79(23.17,27.98) \\
0.001\end{array}$ & $\begin{array}{l}23.82(21.64,25.99) \\
0.001\end{array}$ \\
\hline & $\mathrm{N}$-size & 518 & 518 & 518 \\
\hline & R-square & 0.030 & 0.044 & 0.11 \\
\hline & Adj. R-square & 0.026 & 0.03 & 0.079 \\
\hline & RMSE & 3.899 & 3.895 & 3.776 \\
\hline
\end{tabular}

Ref.: reference categories; ß: Beta coefficient; CI: confidence interval, RMSE: root mean square error, CHEW: community health extension worker, CHO: community health officer.

one, having an internet-enabled phone was associated with an increased score of mHealth knowledge (regression coefficient, $§=1.21$, 95\% CI=0.58-1.82). In model 2, after controlling for cadre, education and health center, having an internet-enabled phone was significantly associated with an increased score of mHealth knowledge $(ß=1.21$, 95\% $\mathrm{CI}=0.62-1.81$ ); In model 3 , after controlling for age, tribe, and marital status the significant effect remained. Doctors compared with CHEW had 1.24 increased scores of mHealth knowledge. Similarly, primary health care providers with high education had 0.99 increased scores of mHealth knowledge compared to those with low education. Age was positively associated with mHealth knowledge ( $§=0.02$, 95\% $\mathrm{CI}=0.01-0.05)$.

Table 3 shows the multivariate linear regression results examining the association between ownership of smart- phone and internet-enabled phone with attitude towards mHealth among primary health care providers. In model 1 , both ownership of smartphone $(\Omega=0.95,95 \% \mathrm{CI}=0.04-1.85)$ and having internet-enabled phone $(\S=1.09$, 95\% $\mathrm{CI}=0.12-2.07)$ were positively associated with increased scores on attitude towards mHealth. In model 2, the effect for both variables increased when we adjusted for Cadre, education, and health center. In model 3 , after controlling for all demographic factors, both ownership of smartphone $(ß=1.00,95 \% \mathrm{CI}=0.12-1.89)$ and having an internet-enabled phone ( $\S=1.14,95 \% \mathrm{CI}: 0.18-2.10)$ resulted in an increased score on attitude towards mHealth among primary health care providers. Knowledge of mHealth $(\beta=0.59,95 \% \mathrm{CI}$ : 0.11-1.06) and increasing age $(§=0.06,95 \% \mathrm{CI}=0.02-0.10)$ were positively associated with attitude towards mHealth.

In model 1 of Table 4 , primary health care providers 
Table 4. A logistic regression model showing the predictors of mHealth usage among primary health care providers

\begin{tabular}{|c|c|c|c|c|}
\hline \multirow[t]{2}{*}{ Variable } & & \multirow{2}{*}{$\begin{array}{l}\text { Model } 1 \\
\text { OR }(95 \% \mathrm{Cl}) ; P \text {-value }\end{array}$} & \multirow{2}{*}{$\begin{array}{l}\text { Model } 2 \\
\text { OR }(95 \% \mathrm{Cl}) ; P \text {-value }\end{array}$} & \multirow{2}{*}{$\begin{array}{l}\text { Model } 3 \\
\text { OR }(95 \% \mathrm{Cl}) ; P \text {-value }\end{array}$} \\
\hline & & & & \\
\hline Own smartphone & Yes & $\begin{array}{l}1.88(1.20,2.93) ; \\
0.005\end{array}$ & $\begin{array}{l}1.38(0.79,2.38) ; \\
0.25\end{array}$ & $\begin{array}{l}1.46(0.83,2.56) ; \\
0.19\end{array}$ \\
\hline $\begin{array}{l}\text { Have internet on } \\
\text { phone }\end{array}$ & Yes & & $\begin{array}{l}0.98(0.54,1.77) ; \\
0.95\end{array}$ & $\begin{array}{l}1.20(0.65,2.22) \\
0.56\end{array}$ \\
\hline \multirow[t]{5}{*}{ Cadre } & CHEW & & & Ref. \\
\hline & $\mathrm{CHO}$ & & $\begin{array}{l}2.86(1.04,7.88) ; \\
0.04\end{array}$ & $\begin{array}{l}2.37(0.85,6.67) ; \\
0.10\end{array}$ \\
\hline & Doctor & & $\begin{array}{l}1.12(0.52,2.40) ; \\
0.77\end{array}$ & $\begin{array}{l}1.63(0.71,3.75) ; \\
0.25\end{array}$ \\
\hline & Nurse/Midwife & & $\begin{array}{l}1.80(0.96,3.37) ; \\
0.07\end{array}$ & $\begin{array}{l}1.54(0.79,2.97) ; \\
0.20\end{array}$ \\
\hline & Others & & $\begin{array}{l}1.03(0.41,2.58) ; \\
0.96\end{array}$ & $\begin{array}{l}1.11(0.42,2.89) ; \\
0.83\end{array}$ \\
\hline \multirow[t]{2}{*}{ Education } & Primary/Secondary & & & Ref. \\
\hline & Tertiary & & $\begin{array}{l}2.10(1.17,3.76) ; \\
0.01\end{array}$ & $\begin{array}{l}1.64(0.84,3.21) \\
0.15\end{array}$ \\
\hline mHealth Knowledge & mHealth Knowledge & & $\begin{array}{l}1.32(1.20,1.45) ; \\
0.001\end{array}$ & $\begin{array}{l}1.32(1.20,1.46) ; \\
0.001\end{array}$ \\
\hline Attitude to mHealth & Attitude to mHealth & & $\begin{array}{l}1.16(1.09,1.23) ; \\
0.001\end{array}$ & $\begin{array}{l}1.15(1.08,1.22) ; \\
0.001\end{array}$ \\
\hline \multirow[t]{2}{*}{ Health Center } & Private (Ref.) & & & Ref. \\
\hline & Public & & & $\begin{array}{l}1.01(0.58,1.72) ; \\
0.98\end{array}$ \\
\hline \multirow[t]{2}{*}{ Sex } & Female & & & Ref. \\
\hline & Male & & & $\begin{array}{l}0.45(0.23,0.89) ; \\
0.02\end{array}$ \\
\hline Age & Age & & & $\begin{array}{l}1.04(1.01,1.07) ; \\
0.01\end{array}$ \\
\hline \multirow[t]{4}{*}{ Tribe } & Yoruba & & & Ref. \\
\hline & Igbo & & & $\begin{array}{l}1.18(0.58,2.41) ; \\
0.65\end{array}$ \\
\hline & Hausa & & & $\begin{array}{l}0.93(0.08,10.57) ; \\
0.94\end{array}$ \\
\hline & Others & & & $\begin{array}{l}0.52(0.19,1.38) \\
0.19\end{array}$ \\
\hline \multirow[t]{5}{*}{ Marital Status } & Married & & & 1.000 \\
\hline & Not married & & & $\begin{array}{l}1.03(0.59,1.82) ; \\
0.89\end{array}$ \\
\hline & $\mathrm{N}$-size & 518 & 518 & 518 \\
\hline & LR chi-square & $7.61(1)=0.006$ & $103.30(9)=0.000$ & $119.85(16)=0.000$ \\
\hline & $\begin{array}{l}\text { Cox \& Snell Pseudo } \\
\mathrm{R}^{2}\end{array}$ & 0.012 & 0.17 & 0.20 \\
\hline
\end{tabular}

Ref: reference categories; OR: odds ratio; CI: confidence interval, LR: likelihood ratio, CHEW: community health extension worker, CHO: community health officer.

who owned smartphones were 1.88 times more likely to use mHealth for maternal and child health services. However, this effect was totally mediated after controlling for cadre, educational status, mHealth knowledge and attitude in Model 2. The effect remained non-significant for both ownership of smartphone and having internet-enabled phone in Model 3. In terms of associations between knowledge of mHealth and attitudes towards mHealth with utilization, primary health care providers with higher scores on mHealth knowledge were 1.32 times more likely to use mHealth for maternal and child health services. Similarly, those with higher scores on attitude towards mHealth were 
1.15 times more likely to use mHealth for maternal and child health services than those with lower scores on attitudes. Lastly, use of mHealth in rendering maternal and child health services was more likely with increasing age of primary health care providers (AOR=1.04, 95\% $\mathrm{CI}=1.01-1.07)$.

\section{DISCUSSION}

The purpose of our study was to assess primary health care providers' knowledge and attitudes towards the use of mobile technology to promote maternal and child health in Nigeria. We found that while owning a smartphone was not a predictor of higher mHealth knowledge, having an internet-enabled phone was a strong predictor of higher mHealth knowledge and positive attitude among primary health care providers. We found that mHealth knowledge and positive attitude were significant predictors of the use of mHealth for maternal and child health.

Although several mHealth interventions are based on the provision of mobile phones to health care providers, ${ }^{30}$ our findings indicate that health care providers' ability to access internet on their mobile phones is critical to mHealth adoption and utilization. Despite the potential benefits that mobile phone ownership offers for maternal and child health service delivery, those benefits could be offset by limited access to internet among health care workers. Findings from other research studies have showed that some health care providers, particularly nurses and midwives, may find the cost of airtime and internet data needed for mHealth too burdensome, even if they are willing to provide services using mHealth technology. ${ }^{2,31,32}$ Considering that more than half of our study population were nurses and midwives, who also constitute the largest proportion of maternal health care providers in Nigeria, there may be the need for some financial support to primary care workers who may be unable to afford both cell phones and internet services in support of maternal and child care services.

In countries like Nigeria where maternal and infant mortality is significantly high, the Ministry of Health can harness mHealth to improve maternal and child health outcomes. One potential strategy is taking advantage of the already widespread ownership of mobile phones among health care providers, if access to internet can be provided to these health care workers. We recommend that mHealth interventions focus on ways to provide sustainable access to internet on health care providers mobile phones for the provision of maternal and child health services.

We also tested whether higher knowledge of mHealth and positive attitudes towards mHealth resulted in use of mobile phones in providing maternal and child health services. We found that both higher knowledge of mHealth and positive attitudes towards mHealth were significantly associated with use of mobile phones in rendering maternal and child health services by primary health care providers. Our findings are consistent with other studies in showing that knowledge and attitudes towards mHealth applications can influence adoption and use in maternal and child health care service delivery in low-resource settings. 8,33 When health care workers are knowledgeable about mHealth applications, they are more likely to use mHealth in the pro- motion of maternal and child health care services. Since positive attitudes of health care workers towards mHealth can increase adoption and use, emphasis should be placed on improving their attitudes towards mHealth. Further studies are needed to explore how to improve health care provider attitudes towards mHealth in care delivery.

The strengths of this paper are three-fold. First, although many prior studies have examined the effect of using mHealth in improving general healthcare, this is one of the few studies that provides evidence of the importance of mHealth use among healthcare providers for maternal and child health services. Second, this study develops two new measuring scales on knowledge toward mHealth use and attitude towards mHealth use, which can be adopted and validated in subsequent studies. Third, this study highlights the effect of knowledge and attitude toward mHealth and how it affects actual implementation, which has rarely been examined in previous studies. It also provides evidence for interventions in enhancing maternal and child health services in a low-income setting.

There are some limitations to this study that provide opportunities for future studies. First, the cross-sectional nature of the study does not allow us to establish causal effects. A longitudinal study of health professional's knowledge, attitude, and actual use of mHealth services will provide a more robust causal explanation. Second, due to the research design used in this study, we are not able to generalize to the entire healthcare profession. Future studies will benefit from a random sample of healthcare professionals from a healthcare facility in each state in Nigeria.

\section{CONCLUSIONS}

The results of our study show that access to internet-enabled phone increased primary health care providers' knowledge of mHealth. Knowledge of mHealth in turn increased positive attitudes towards mHealth. Furthermore, primary health care providers with high knowledge of mHealth and positive attitudes towards mHealth were more likely to use mHealth in providing maternal and child health services. The results imply that although mHealth technology count as healthcare strengthening tools and have the potential to improve maternal and child health in Sub-Saharan African Countries, use of these tools by primary health care providers is affected by knowledge and attitude towards mHealth. Thus, mHealth promoting interventions must focus on improving knowledge and attitudes among primary health care providers. Based on the results, interventions that focus on increasing access to internetenabled mobile technologies are needed to improve knowledge, attitudes, and use of mHealth for maternal and child health services.

Acknowledgements: We are grateful to Dr Adeyanju Oyetoyan, medical officer of health, for his assistance during data collection. We also thank the study participants for the time and effort taken to provide the information for this research. 
Author contributions: Conception and design: MRB, BR-K, GOB. Collection and assembly of data: MRB, BR-K, AS. Data analysis and interpretation: MRB, GOB, YJA, EAA. Manuscript writing: All authors. Final approval of manuscript: All authors

Competing interests: The authors completed the Unified Competing Interest form at www.icmje.org/coi_discloauthor), and declare no conflicts of interest.

Correspondence to:

Mobolanle R Balogun

MBBS, MPH, FMCPH, FWACP

Department of Community Health \& Primary Care, College of Medicine of the University of Lagos, Lagos, Nigeria mbalogun@cmul.edu.ng 


\section{REFERENCES}

1. World Health Organization. MHealth: New Horizons for Health through Mobile Technologies.; 2019. https://www.who.int/goe/publications/goe_mhe alth web.pdf.

2. Gagnon M-P, Ngangue P, Payne-Gagnon J, Desmartis M. m-Health adoption by healthcare professionals: A systematic review. Journal of the American Medical Informatics Association. 2015;23(1):212-220.

3. Amoakoh-Coleman M, Borgstein AB-J, Sondaal SF, et al. Effectiveness of mHealth Interventions Targeting Health Care Workers to Improve Pregnancy Outcomes in Low- and Middle-Income Countries: A Systematic Review. Journal of Medical Internet Research. 2016;18(8):e226. doi:10.2196/imir.5533

4. Modi D, Gopalan R, Shah S, et al. Development and formative evaluation of an innovative mHealth intervention for improving coverage of communitybased maternal, newborn and child health services in rural areas of India. Global Health Action. 2015;8(1):26769. doi:10.3402/gha.v8.26769

5. Colaci D, Chaudhri S, Vasan A. mHealth interventions in low-income countries to address maternal health: A systematic review. Annals of global health. 2016;82(5):922-935. doi:10.1016/j.aog h.2016.09.001

6. Higgs ES, Goldberg AB, Labrique AB, Cook SH, Schmid C, Cole CF, et al. Understanding the role of mHealth and other media interventions for behavior change to enhance child survival and development in low-and middle-income countries: An evidence review. Journal of Health Communication. 2014;19(sup1):164-189. doi:10.1080/10810730.2014.9 $\underline{29763}$

7. Balakrishnan R, Gopichandran V, Chaturvedi S, Chatterjee R, Mahapatra T, Chaudhuri I. Continuum of Care Services for Maternal and Child Health using mobile technology-a health system strengthening strategy in low and middle income countries. $B M C$ medical informatics and decision making. 2016;16(1):84. doi:10.1186/s12911-016-0326-Z

8. Sondaal SFV, Browne JL, Amoakoh-Coleman M, et al. Assessing the Effect of mHealth Interventions in Improving Maternal and Neonatal Care in Low- and Middle-Income Countries: A Systematic Review. Li D, ed. PLOS ONE. 2016;11(5):e0154664. doi:10.1371/jour nal.pone.0154664
9. Watterson JL, Walsh J, Madeka I. Using mHealth to improve usage of antenatal care, postnatal care, and immunization: A systematic review of the literature. BioMed research international. 2015;2015. doi:10.115 $\underline{5 / 2015 / 153402}$

10. Ngabo F, Nguimfack J, Nwaigwe F, Mugeni C, Muhoza D, Wilson DR, et al. Designing and Implementing an Innovative SMS-based alert system (RapidSMS-MCH) to monitor pregnancy and reduce maternal and child deaths in Rwanda. The Pan African Medical Journal. 2012;13.

11. Lund S, Hemed M, Nielsen BB, Said A, Said K, Makungu M, et al. Mobile phones as a health communication tool to improve skilled attendance at delivery in Zanzibar: A cluster - randomised controlled trial. BJOG: An International Journal of Obstetrics \& Gynaecology. 2012;119(10):1256-1264. doi:10.1111/i.1471-0528.2012.03413.x

12. Lee SH, Nurmatov UB, Nwaru BI, Mukherjee M, Grant L, Pagliari C. Effectiveness of mHealth interventions for maternal, newborn and child health in low- and middle-income countries: Systematic review and meta-analysis. J Glob Health. 2016;6(1):010401. doi:10.7189/jogh.06.010401

13. Moss W, Darmstadt GL, Marsh DR, Black RE, Santosham M. Research priorities for the reduction of perinatal and neonatal morbidity and mortality in developing country communities. Journal of Perinatology. 2002;22(6):484-495. doi:10.1038/sj.jp.7 $\underline{210743}$

14. World Health Organization. Maternal health in Nigeria: Generating information for action 2019. 2019. https://www.who.int/reproductivehealth/mater nal-health-nigeria/en/. Accessed February 14, 2019.

15. WHO, UNICEF, UNFPA, World Bank Group and the United Nations Population Division. Trends in Maternal Mortality: 1990 to 2015. Estimates by WHO, UNICEF. UNFPA, World Bank Group and the United Nations Population Division.; 2015. https://www.wh o.int/reproductivehealth/publications/monitoring/ma ternal-mortality-2015/en/.

16. Hug L, Alexander M, You D, Alkema L. National, regional, and global levels and trends in neonatal mortality between 1990 and 2017, with scenariobased projections to 2030: A systematic analysis. The Lancet Global Health. 2019;7(6):e710-e720. doi:10.10 16/s2214-109x(19)30163-9 
17. United Nations Inter-agency Group for Child Mortality Estimation. Under-5 Mortality Rate - Total 2018. https://childmortality.org/data. Accessed Winter 2019.

18. Oyeyemi SO, Wynn R. Giving cell phones to pregnant women and improving services may increase primary health facility utilization: A casecontrol study of a Nigerian project. Reproductive health. 2014;11(1):8. doi:10.1186/1742-4755-11-8

19. Chib A, van Velthoven MH, Car J. mHealth adoption in low-resource environments: A review of the use of mobile healthcare in developing countries. Journal of health communication. 2015;20(1):4-34. do $\mathrm{i}: 10.1080 / 10810730.2013 .864735$

20. Bello IS, Arogundade FA, Sanusi AA, Ezeoma IT, Abioye-Kuteyi EA, Akinsola A. Knowledge and utilization of Information Technology among health care professionals and students in Ile-Ife, Nigeria: A case study of a university teaching hospital. Journal of Medical Internet Research. 2004;6(4):e45. doi:10.2 196/jmir.6.4.e45

21. Gour N, Srivastava D. Knowledge of computer among healthcare professionals of India: A key toward e-health. Telemedicine and e-Health. 2010;16(9):957-962. doi:10.1089/tmj.2010.0049

22. Olok GT, Yagos WO, Ovuga E. Knowledge and attitudes of doctors towards e-health use in healthcare delivery in government and private hospitals in Northern Uganda: A cross-sectional study. BMC medical informatics and decision making. 2015;15(1):87. doi:10.1186/s12911-015-0209-8

23. Sukums F, Mensah N, Mpembeni R, Kaltschmidt J, Haefeli WE, Blank A. Health workers' knowledge of and attitudes towards computer applications in rural African health facilities. Global Health Action. 2014;7(1):24534. doi:10.3402/gha.v7.24534

24. Ajayi A, Balogun M. Knowledge and Attitudes towards Mobile Phone Use to Promote Maternal and Child Health among Women in Mushin, Lagos State. UNILAG Journal of Medicine, Science and Technology. 2015;3(1):45-57.
25. Jennings L, Ong'ech J, Simiyu R, Sirengo M, Kassaye S. Exploring the use of mobile phone technology for the enhancement of the prevention of mother-to-child transmission of HIV program in Nyanza, Kenya: A qualitative study. BMC public health. 2013;13(1):1131. doi:10.1186/1471-2458-13-1 131

26. Price M, Williamson D, McCandless R, et al. Hispanic migrant farm workers' attitudes toward mobile phone-based telehealth for management of chronic health conditions. Journal of Medical Internet Research. 2013;15(4):e76. doi:10.2196/imir.2500

27. Boateng GO, Neilands TB, Frongillo EA, MelgarQuiñonez HR, Young SL. Best practices for developing and validating scales for health, social, and behavioral research: A primer. Frontiers in public health. 2018;6. doi:10.3389/fpubh.2018.00149

28. Bernstein IH, Nunnally JC. Psychometric Theory. New York: McGraw-Hill; 1992.

29. StataCorp. Stata Statistical Software: Release 14. College Station, TX: StataCorp LP; 2015.

30. Martínez-Fernández A, Lobos-Medina I, DíazMolina CA, Chen-Cruz MF, Prieto-Egido I. TulaSalud: An m-health system for maternal and infant mortality reduction in Guatemala. Journal of telemedicine and telecare. 2015;21(5):283-291. doi:1 $\underline{0.1177 / 1357633 X 15575830}$

31. Watkins JOTA, Goudge J, Gómez-Olivé FX, Griffiths F. Mobile phone use among patients and health workers to enhance primary healthcare: A qualitative study in rural South Africa. Social Science \& Medicine. 2018;198:139-147. doi:10.1016/j.socscim ed.2018.01.011

32. Medhanyie AA, Little A, Yebyo H, Spigt M, Tadesse K, Blanco R, et al. Health workers' experiences, barriers, preferences and motivating factors in using mHealth forms in Ethiopia. Human resources for health. 2015;13(1):2. doi:10.1186/147 8-4491-13-2

33. Chen H, Chai Y, Dong L, Niu W, Zhang P. Effectiveness and appropriateness of mHealth interventions for maternal and child health: Systematic review. JMIR Mhealth Uhealth. 2018;6(1):e7. doi:10.2196/mhealth.8998 


\section{SUPPLEMENTARY MATERIALS}

\section{Online Supplementary Document}

Download: https://www.joghr.org/article/13507-using-mobile-phones-to-promote-maternal-and-child-healthknowledge-and-attitudes-of-primary-health-care-providers-in-southwest-nigeria/attachment/37266.docx 